\title{
REVIEW
}

\section{Unravelling the genetic complexity of autoimmune thyroid disease: HLA, CTLA-4 and beyond}

\author{
M. J. SIMMONDS* \& S. C. L. GOUGH*†*Division of Medical Sciences, University of Birmingham, Institute of Biomedical Research \\ and $\dagger$ Birmingham Heartlands Hospital, Birmingham,UK
}

(Accepted for publication 22 January 2004)

\begin{abstract}
SUMMARY
The autoimmune thyroid diseases (AITDs) including Graves' disease (GD) and autoimmune hypothyroidism $(\mathrm{AIH})$ are the commonest of the autoimmune conditions affecting $2-5 \%$ of the western population. Twin studies have clearly demonstrated that AITDs are caused by a combination of both environmental and genetic factors. Association of the HLA class II region with AITD has been documented for over 20 years now, but the primary aetiological variant in this region remains unknown. More recently the CTLA-4 gene region has been identified as the second locus conferring susceptibility to AITD. In contrast to HLA, a polymorphism of the CTLA-4 gene, which encodes an important negative regulator of the immune system, has been identified as a candidate for a primary determinant for AITD. A large number of candidate gene and genome wide linkage studies have been involved in the search for the elusive 'third' locus. The thyroglobulin ( Tg) gene in humans maps to chromosome 8q, which has been linked in family studies to AITD. A number of association studies in humans and the mouse model for AITD are beginning to implicate the Tg gene although convincing evidence for a primary causative role is still needed. The establishment of large DNA disease resources along with more detailed genetic maps and the development of faster, more effective, high throughput genotyping and sequencing methods, provides some sense of optimism that novel loci will be identified in the near future and the complex aetiology of AITD will be further unraveled.
\end{abstract}

Keywords autoimmune thyroid disease HLA CTLA-4 gene

\section{INTRODUCTION}

The autoimmune thyroid diseases (AITDs) including Graves' disease (GD) and autoimmune hypothyroidism (AIH) are the commonest of the autoimmune conditions affecting $2-5 \%$ of the western population $[1,2]$. Patients with GD present with clinical manifestations of an overactive thyroid gland (Table 1), a diffuse swelling of the gland and in the majority of cases thyroid eye disease. A high proportion of patients present with increased serum titres of thyroid autoantibodies including antibodies directed against the thyrotropin (thyroid-stimulating hormone) receptor (TSHR) which is thought to be the primary autoantigen. In contrast patients with autoimmune hypothyroidism (AIH) present with the clinical manisfestations of an underactive thyroid gland (Table 1), diffuse swelling of the gland and significant titres of thyroid peroxidase and/or thyroglobulin autoantibodies. In addition to the increased morbidity associated with hypo and

Correspondence: Dr S. C. L. Gough, Department of Medicine, University of Birmingham, Birmingham Heartlands Hospital, Bordesley Green East, Birmingham. B9 5SS. UK.

E-mail: s.c.gough@bham.ac.uk hyperthyroidism, which requires specialist expertise, AITD itself is associated with an increased mortality including that from cardiovascular diseases.

The reasons why patients with autoimmune thyroid disease fail to maintain immune tolerance to thyroid protein(s) is unknown although both environmental and genetic factors play an important role in the development of disease. The fact that AITD clusters in individuals with other autoimmune diseases, including for example type 1 diabetes (T1D), rheumatoid arthritis and multiple sclerosis [3], supports the hypothesis that the common autoimmune diseases share at least some aetiological mechanisms.

It is well known that the principle effectors of the immune system are $\mathrm{B}$ and $\mathrm{T}$ lymphocytes and that lymphocytes can be divided into T-helper (Th) cells, which express CD4+ surface antigens, and T-cytotoxic (Tc) cells, which express CD8+ surface antigens. The CD4+ Th precursor cells are further subdivided into two populations, Th1 and Th2 cells. Th1 cells secrete interleukin-2 (IL-2), interferon- $\gamma(\mathrm{IFN}-\gamma)$ and tumour necrosis factor alpha (TNF- $\alpha$ ), which regulate the cellular-mediated immune response and the induction of tissue damage [4,5]. Th2 cells secrete interleukins, 
Table 1. Clinical features of Graves' disease and autoimmune hypothyroidism

Clinical features of GD

Clinical features of AIH

\begin{tabular}{ll}
\hline Hyperthyroidism & Hypothyroidism \\
Diffuse goitre & Diffuse goitre \\
Tachycardia & Bradycardia \\
Proximal myopathy & Pericardial effusion \\
Bowel frequency & Ascites \\
Heat intolerance, sweaty hands & Gruff voice, dry skin, coarse features \\
Tremor & Hypothermia \\
Thyroid eye disease &
\end{tabular}

IL-4, IL-5, IL-6 and IL-10, and are activated to provide help to B lymphocytes for specific immunoglobulin $(\mathrm{Ig})$ production $[4,5]$. Thyroid autoimmunity has been shown to occur via a two stage process [6]. Stage one involves the increased appearance of intrathyroid antigen presenting cells (APC) [7] that carry and present thyroid autoantigens to Th cells. Stage two involves lymphocytes interacting with the presented autoantigens, leading to the generation of a large number of autoreactive CD4+ Th lymphocytes, CD8+ Tc lymphocytes and antibody-producing B lymphocytes that infiltrate the thyroid parenchyma. This turns the thyroid gland into a 'battlefield' where the outcome of the interaction between the thyrocytes and infiltrating lymphocytes determines the different clinical outcomes of AITD, believed to be due to differences in the cytokines profile in the thyroid gland upon infiltration (Fig. 1). In AIH there appears to be a prevalence of Th1 cytokines, leading to a predominance of T lymphocyte immunity, causing increased immune destruction of the thyroid cells and hypothyroidism. In GD, on the other hand, there appears to be a predominance of Th2 type inflammatory cytokines [4,8-10] and B lymphocyte immunity producing high levels of IgG antibodies specific for the TSHR which can activate the receptor, causing thyroid cell hyperplasia and hyperthyroidism. The fact however, that both diseases can develop in the same individual at different time points suggest that immunological categorizations may be overly simplistic and that cytokine patterns are dynamic processes. This review will focus on the genetic contribution to AITD which to a large extent involves the role of immune response genes.

\section{THE GENETIC BACKGROUND TO AITD}

Strong evidence for a genetic basis to AITD comes from family studies demonstrating that a family history of GD has been reported in approximately $50 \%$ of patients [11]. Early twin studies estimated the concordance rates for disease in identical (monozygotic) MZ twins to be $50-70 \%$ and 3-25\% for nonidentical (dizygotic) DZ twins for GD [12]. More recent studies show concordance rates in GD of 35\% for MZ twins and 3-9\% for DZ twins [13] and rates of $55 \%$ for MZ twins and $<1 \%$ DZ twins for AIH [14]. As concordance rates for disease fall well below $100 \%$ in $\mathrm{MZ}$ twins, that share identical DNA, environmental (nongenetic) factors must also play a role in the development of AITD. The different environmental factors that have been proposed include bacterial [15] or viral infection [16], stressful life events [17], synthetic chemicals [18] and iodine uptake [19] but, to date,

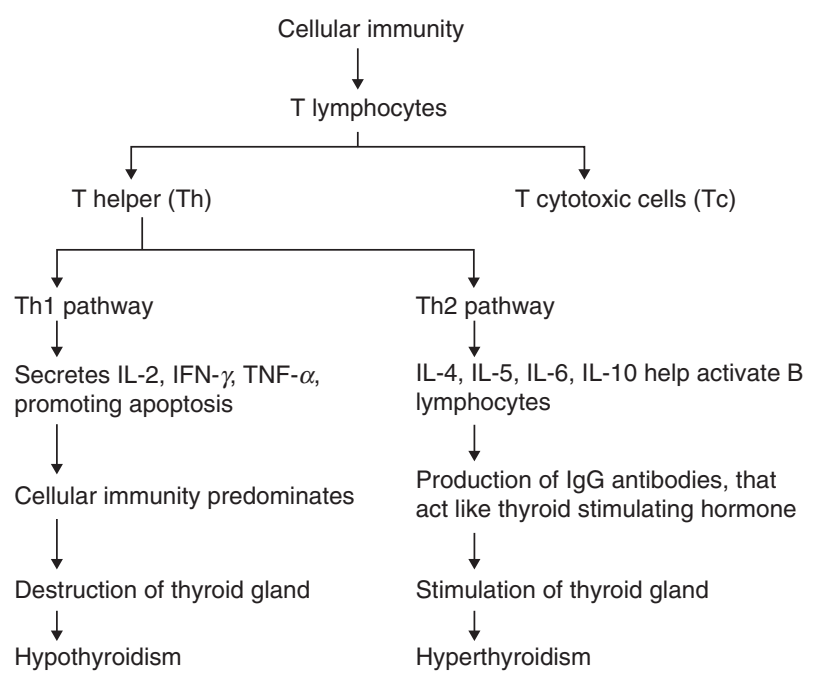

Fig. 1. Simplified version of how Th1 and Th2 responses lead to the different clinical presentations of AITD.

conclusive evidence for any is lacking and associations still remain largely controversial.

Pioneering work in T1D suggests that most autoimmune diseases are polygenic in nature implying that no single gene is either sufficient or necessary to cause disease and that a combination of common disease genes encode susceptibility [20]. Although environmental agents are undoubtedly important for the development of AITD in susceptible individuals, statistical modelling suggests that around $79 \%$ of the predisposition to GD is due to genetic factors [13].

Two main approaches have been employed to locate susceptibility loci for AITD, namely case control candidate gene studies and genome-wide linkage screens [21]. Case control candidate gene studies have been employed to investigate numerous genes for association with AITD, but to date, only the human leucocyte region (HLA) on chromosome 6p21 and the cytotoxic T lymphocyte associated 4 (CTLA-4) gene on chromosome 2 q33 have been consistently shown to be associated with disease. Estimates suggest that these two gene regions may account for around $50 \%$ of the genetic contribution to GD in the UK population $[22,23]$ and will therefore be discussed in more detail.

\section{HUMAN LEUCOCYTE REGION ASSOCIATION WITH AITD}

The HLA region can be split into three different parts, class I, class II and class III (Fig. 2a). The class I region (Fig. 2a), encodes HLA-A, -B and -C molecules, expressed on the cell surface of nucleated cells and are involved in the presentation of endogenous antigens to $\mathrm{CD} 8+\mathrm{Tc}$ cells. The class II region (Fig. 2b) encodes many membrane bound proteins expressed on the cell surface of B-lymphocytes, macrophages, dendritic cells and activated $\mathrm{T}$ lymphocytes, that are involved in the processing and presentation of exogenous antigens to CD4+ Th cells. At the telomeric end of the class II region are the DR and DQ genes which code the $\alpha$ and $\beta$ peptide chains of the HLA class II molecules. The genes that encode protein involved in processing antigens for presentation lie centrally within the class II region and include the 
(a) Class I (2000-4000 kb)

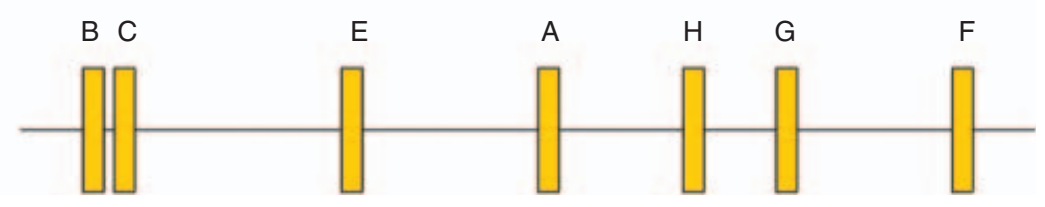

(b) Class II (1-1000 kb)

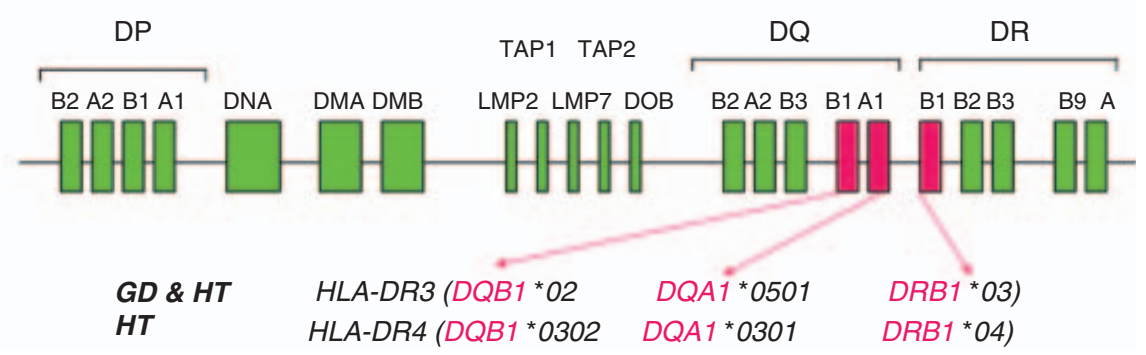

(c) Class III (1000-2000 kb)

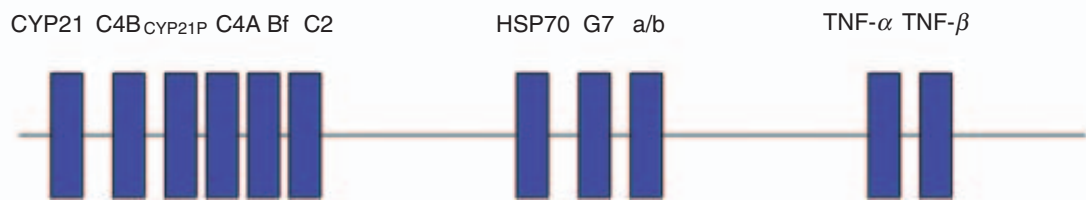

Fig. 2. (a) HLA class I gene region. (b) HLA class II gene region with known haplotypes associated with GD and HT (transport associated with antigen processing genes (TAP1 and TAP2) and large multifunctional protein $(L M P)$ ). (c) HLA class II gene regions (Heat shock protein $(H S P)$, tumour necrosis factor $(T N F))$.

large multifunctional proteasomes (LMP 2 and LMP 7), transporter associated with antigen processing genes (TAP1 and TAP2) and the DM genes involved in loading of antigenic peptides onto class II molecules. The DP genes, DPA1 and DPB1, code for the $\alpha$ and $\beta$ peptide chains that constitute the class II molecule and like DR and DQ are also involved in antigen presentation to CD4+ Th cells. Finally, the class III region (Fig. 2c) is located between the class I and class II regions and contains, amongst others, genes encoding components of the complement region ( $\mathrm{C} 2, \mathrm{C} 4$ and $\mathrm{Bf})$, the heat shock protein (HSP70) and tumour necrosis factor (TNF).

\section{HLA ASSOCIATION WITH GD}

Initial association studies in GD focused on the Class I region, with association of the HLA-A8 region [24] and in particular the HLA-B8 region [25,26] with disease. Further studies demonstrated strong linkage disequilibrium (LD) between HLA-B8 and HLA-DR3 [27] suggesting that the association of HLA-B8 may be secondary to DR3 and that the HLA-DR region played a greater role [28]. Such assumptions were based on the finding of greater degrees of association between disease and DR3 compared with HLA-B8. Whilst such assumptions may be correct a comprehensive statistical analysis has not been performed and class I genes can not therefore be completely excluded from having an independent effect. However, the majority of future studies have focused on the HLA class II region.

As has been mentioned earlier, products of the class II gene region aid in antigen presentation to $\mathrm{CD} 4+\mathrm{Th}$ cells. The DRB1,
$D Q A 1$ and $D Q B 1$ genes are highly polymorphic and these molecules play a major role in maintaining tolerance to self-thyroid antigens. With aberrant expression being seen on follicular cells (the target cells for GD) and on activated lymphocytes, the class II genes and molecules are attractive primary candidates for involvement with AITD.

Farid et al.in 1979 [28] were the first group to use a case control based method to show a strong association with HLA-DR3 in Canadian Caucasians, with several other studies replicating this result [29-31]. Despite the strong association of DR3 with disease in Caucasians it has been observed that DR3 frequency is reduced in Sardinian GD patients [31] and disease association in the Japanese population seemed to be due exclusively to class I molecules [32]. These and other studies suggest that either different HLA associations are contributing to disease in different populations or that those loci showing positive association are in LD with an as yet unknown primary disease determinant in the HLA region.

A number of studies have subsequently replicated association between GD and DR3 in both case control and family based datasets and gone on to demonstrate association between the DRB1*03-DQB1*02-DQA1*0501 extended haplotype and GD conferring relative risks (RR) for the development of disease of between 1.9 and 3.8 [2]. Attempts have been made to statistically 'split' the haplotype to determine whether individual class II genes are conferring susceptibility to disease or whether this really is a haplotype (trans-) effect. Yanagawa et al. [33] have reported a significant increase in DQA $1 * 0501$ in USA Caucasian subjects with GD and a trend towards association of DR3 with GD, and proposed that the DQA1*0501 association was indepen- 
dent of DR3 with DQA1*0501 conferring a greater risk [33]. Confirmation of stronger independent association of DQA1*0501 with GD was shown by the result still being present in DR3 negative (DR3-ve) subjects [34]. However, this study did not correct for the number of alleles seen, which when performed leads to a nonsignificant finding. Other authors have reported association of DQA1*0501 with GD and others have attempted to determine if association of the DQA1*0501 with GD is the result of LD with DR3 $[35,36]$, or whether $D Q A$ posed a greater, independent risk [37,38] (see Table 2, Fig. 2b). Inconsistencies reported in such studies are probably the result of small sample groups and comparisons between differing geographical and ethnic backgrounds.

Heward et al. 1998 [39] performed the largest case control investigation of association of the class II region with GD in a UK population to date, and provided confirmation in an independent family dataset. Strong association of both DRB1*03 $(\mathrm{RR}=2 \cdot 45)$ and DQA1*0501 $(\mathrm{RR}=2 \cdot 26)$ was found but no independent effect of DQA $1 * 0501$ was seen. Due to linkage between DRB1*03, DQB1*02 and DQA1*0501, distribution of the haplotype DRB1*03-DQB1*02-DQA1*0501 between GD and control subjects was analysed, showing association with GD $(\mathrm{RR}=2 \cdot 52)$ which was confirmed in the family dataset [39].

In summary, therefore, there are consistent associations between the HLA class II genes and GD although at the present time it remains unclear whether the primary susceptibility is the result of a haplotype or single locus effect. Large sample sizes with accurate class II subtyping subject to a logistic regression analysis may be one way in which this could be resolved. Ultimately, it would be important to know whether polymorphisms leading to specific amino acid changes within peptide binding pockets of HLA class II molecules are determining the nature of antigen presentation and in turn the $\mathrm{T}$ cell repertoire conferring susceptibility to GD.

\section{HLA ASSOCIATIONS WITH AIH}

A similar approach to detecting association of AIH with the HLA region was adopted with initial studies focusing on the class I region [40] and then subsequently the class II region.

Associations that have been proposed for AIH have been less consistent than those with GD and HLA-DR3-HLA-DQw2, HLA-DR5, HLA-DR4, HLA-DQA1*0402 (Table 2 and Fig. 2b) have all been reported to be associated. The reasons for the lack of consistent associations with AIH could be due to the fact that large datasets have not been collected because patients are being treated by their local doctors and not attending specific clinics where recruitment of patients is easier. It seems likely however, that AIH is also associated with DR3 [36,41].

Table 2. Case control association studies of the HLA gene region with GD and HT

\begin{tabular}{|c|c|c|c|c|c|c|}
\hline Author/year & Reference & $\begin{array}{l}\text { Size of data } \\
\text { set }(n)\end{array}$ & Population & $\begin{array}{l}\text { AITD } \\
\text { disease }\end{array}$ & HLA association & $\begin{array}{r}\text { Relative } \\
\text { risk (RR) }\end{array}$ \\
\hline Yanagawa et al. 1993 & [33] & 169 & Caucasian (USA) & GD & $\begin{array}{l}\text { HLA-DR3 } \\
\text { DQA1*0501 }\end{array}$ & $\begin{array}{l}2 \cdot 46 \\
3 \cdot 71\end{array}$ \\
\hline Barlow et al. 1996 & [34] & 187 & Caucasian (UK) & GD & $\begin{array}{l}\text { HLA-DR3 } \\
\text { DQA1*0501 }\end{array}$ & $\begin{array}{l}2 \cdot 7 \\
3 \cdot 8\end{array}$ \\
\hline Magklabruks et al. 1991 & [85] & 130 & Caucasian (USA) & GD & $\begin{array}{l}\text { HLA-DR3 } \\
\text { DQB1 } * 0201 / 3 \dagger\end{array}$ & $\begin{array}{l}3.38 \\
7 \cdot 39 \dagger\end{array}$ \\
\hline Badenhoop et al. 1992 & [86] & 346 & Caucasian (UK \& German) & GD & HLA-DR3 & $2 \cdot 26$ \\
\hline Badenhoop et al. 1995 & [87] & 542 & $\begin{array}{l}\text { Caucasians (German } \\
\quad \& \text { Canadian) }\end{array}$ & GD & DQA1*0501 & $2 \cdot 5$ \\
\hline Cuddihy et al. 1996 & [35] & 218 & Caucasian (USA) & GD & $\begin{array}{l}\text { HLA-DR3 } \\
\text { DQA } 1 * 0501 \dagger\end{array}$ & $\begin{array}{l}3 \cdot 5 \\
1 \cdot 8 \dagger\end{array}$ \\
\hline Heward et al. 1998 & [39] & 592 & Caucasian (UK) & GD & DRB1 $* 0304-D Q B 1 * 02-D Q A 1 * 0501$ & $2 \cdot 72$ \\
\hline Yanagawa et al. 1994 & [38] & 237 & Caucasian (USA) & GD & $\begin{array}{l}\text { HLA-DR3 } \\
\text { DQA1*0501 }\end{array}$ & $\begin{array}{l}2 \cdot 4 \\
3 \cdot 25\end{array}$ \\
\hline Maciel et al. 2001 & [37] & 241 & Brazilian & GD & $\begin{array}{l}\text { DRB1 } * 0301 \\
\text { DQA1 } * 0501\end{array}$ & $\begin{array}{l}2 \cdot 8 \\
3 \cdot 74\end{array}$ \\
\hline Philippou et al. 2001 & [88] & $\begin{array}{l}221 \\
27(\mathrm{~F})\end{array}$ & Greek & GD & DRB1*0301-DQA1*0501 & $8.4(\mathrm{M})$ \\
\hline Bech et al. 1977 & [27] & $\begin{array}{r}2053 \\
243\end{array}$ & Caucasian (Danish) & GD & $\begin{array}{l}\text { HLA-B8 } \dagger \\
\text { HLA-Dw3 }\end{array}$ & $\begin{array}{l}2 \cdot 8 \dagger \\
3 \cdot 9\end{array}$ \\
\hline Moens et al. 1978 & [40] & 262 & Caucasians (Canadian) & HT & HLA-DRw3 & $3 \cdot 49$ \\
\hline Weissel et al. 1980 & [89] & 197 & Caucasian (Austrian) & HT & HLA-DR5 & $3 \cdot 16$ \\
\hline Tandon et al. 1991 & [41] & 186 & Caucasian (UK) & HT & HLA-DR3-HLA-DQw2 & $2 \cdot 23$ \\
\hline Jenkins et al. 1992 & [90] & 143 & Caucasian (UK) & HT & $\begin{array}{l}\text { DQA1 } * 0402 \\
\text { DRB1 } \\
\text { DQB1 }\end{array}$ & $\begin{array}{l}2 \cdot 7 \\
\mathrm{~N} / \mathrm{S} \\
\mathrm{N} / \mathrm{S}\end{array}$ \\
\hline Wan et al. 1995 & [91] & 388 & Japanese & HT & $\begin{array}{l}\text { DRB4 } * 0101 \\
\text { HLA-A2 }\end{array}$ & $\begin{array}{l}4 \cdot 48 \\
2 \cdot 03\end{array}$ \\
\hline Petrone et al. 2001 & [92] & 427 & Caucasian (Italian) & HT & HLA-DRB1*04-DQB1-0301 & 4 \\
\hline Hunt et al. 2001 & [36] & 344 & Caucasian (UK) & HT & DRB $1 * 03$ & $4 \cdot 0$ \\
\hline
\end{tabular}

$\uparrow$ Result due to LD with HLA-DR3. 


\section{CTLA-4 ASSOCIATION WITH AITD}

The $\mathrm{T}$ cell receptor (TCR) dictates $\mathrm{T}$ cell specificity and plays a central role in initiating activation of the immune response. Interaction with a presented antigen is not sufficient alone to activate a naïve $\mathrm{T}$ cell and a second costimulatory signal is required, therefore making T cell activation a two step process [42]. Step one involves generation of an initial signal (signal 1) through interaction of the antigenic peptide with the TCR-CD3 complex. Step 2 involves a subsequent antigen-nonspecific costimulatory signal (signal 2) provided primarily by the interaction of the CD28 molecule on T cells with B7 molecules (CD80 or CD86) expressed on activated macrophages. Signalling through CD28 expressed on activated and resting $\mathrm{T}$ cells provides a positive costimulatory signal to T cells. As a method of controlling up-regulation, the CTLA-4 molecule, a homolog of CD28, expressed on activated $\mathrm{T}$ cells also interacts with $\mathrm{B} 7$ molecules to provide an inhibitory signal, leading to the down-regulation of T cell activation (Fig. 3). Engagement of the TCR-CD3 complex with presented antigen causes induction of CTLA-4, with CTLA-4 being readily detected within $24 \mathrm{~h}$ of stimulation, with maximal expression within 2/3 days [43]. Levels of CTLA-4 expression are increased by a CD28-generated costimulatory feedback that effectively provides braking in proportion to acceleration from CD28 (reviewed in [44]). As CTLA-4-CD28 molecules control the rate of $\mathrm{T}$ cell activation and to a large extent the fate of the immune response they are ideal candidates for a role in the development of AITD.

\section{CD28, CTLA-4 AND AITD}

The genes encoding CD28 and CTLA-4 have been mapped to human chromosome 2 q33 and until recently there were only four known polymorphisms of CTLA-4 including [1] a dinucleotide repeat microsatellite polymorphism $C T L A 4(\mathrm{AT}) \mathrm{n}$ in the $3^{\prime}$

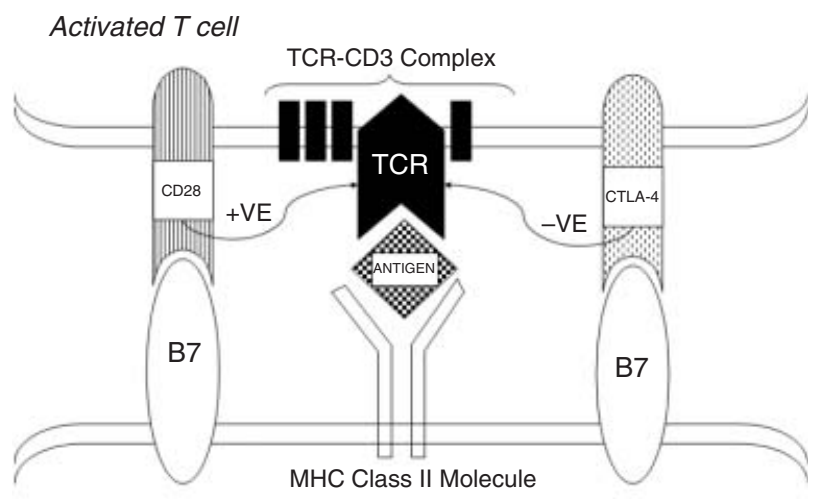

Antigen Presenting Cell

Fig. 3. The stimulatory pathway of CD28 and the antagonist effect of CTLA-4 on Th cell activation. T cell activation occurs via a two stage process. Stage 1 involves generation of a signal via the interaction of a presented antigen with the TCR-CD3 complex. Stage 2 of T cell activation involves a costimulatory signal from CD28 interaction with B7. Regulation of this second stage of $\mathrm{T}$ cell activation is provided by a down regulation of $\mathrm{T}$ cell activation by CTLA-4. Due to the negative control function of CTLA-4, functional mutations in this gene could increase susceptibility to autoimmune thyroid disease. untranslated region of exon 4 [2], an A to $\mathrm{G}$ single nucleotide polymorphism (SNP) (CTLA4(49)A/G) in exon 1 encoding a threonine to alanine substitution at codon 17 and [3] a $\mathrm{C}$ to $\mathrm{T}$ SNP $(C T L A 4[-318] C / T)$ in the promoter relative to the exon 1 start site (Table 3 ). The fourth, a $\mathrm{C}$ to $\mathrm{T}$ SNP in intron 1 of CTLA4 (CTLA4(1822)C/T), has been identified and been reported to be associated with GD [45]. Yanagawa et al. in 1995 [46] were the first group to report an association of polymorphism of CTLA-4 with GD. A 106 bp allele of the CTLA4(AT)n microsatellite was found to be increased in subjects with GD compared with control subjects. Investigation of the CTLA4(49)A/G polymorphism subsequently showed association of the $\mathrm{G}$ allele, and the $106 \mathrm{bp}$ allele of the CTLA4(AT)n microsatellite [47] with GD and T1D with the $106 \mathrm{bp}$ and G alleles demonstrating LD. Since the initial report of association with GD in 1995 a large number of subsequent studies have reported association of CTLA-4 polymorphism with a variety of autoimmune diseases in many different populations (Table 3 ). Replication within two UK family datasets confirmed linkage and association of the $\mathrm{G}$ allele at CTLA4(49)A/G and the $106 \mathrm{bp}$ allele at $C T L A 4(\mathrm{AT}) \mathrm{n}$ with GD $[22,48]$. Estimates by Vaidya et al. [22] suggest that in the UK the CTLA4 locus $(\lambda \mathrm{s}=2 \cdot 2)$ confers $29-34 \%$ of the total genetic susceptibility to GD, greater than the estimated $17-20 \%$ conferred by the MHC $(\lambda s=1 \cdot 6)$. Further in vitro studies have supported a functional role for polymorphism of CTLA-4 [49,50].

Associations of a polymorphism within a gene reported in case control and family based studies do not imply a primary association with disease. The only conclusions that can be drawn are that the polymorphism is associated with disease and that this association may be the result of LD with another polymorphism either within the gene of interest or a neighbouring gene. Functional differences between genotypes are supportive but merely demonstrate a difference between genotypes which may or may not be contributing to disease. Regarding polymorphism of $C T L A-4$ it is just as likely that the association with disease is secondary to a primary locus in either CD28 or ICOS which are in close vicinity of $C T L A-4$ on chromosome $2 \mathrm{q} 33$ only $123 \mathrm{~kb}$ and $58 \mathrm{~kb}$, respectively, from $C T L A-4$. Recently however, in a major effort to identify the primary aetiological variant in this region, Ueda et al. [51] re-sequenced the $300 \mathrm{~kb}$ CD28-CTLA4-ICOS region, detecting 108 SNPs. The SNPs were then scored in 384 GD cases and 652 control subjects and the extent of LD across the CD28-CTLA4-ICOS region was determined (Fig. 4). CTLA4 and the $5^{\prime}$ region of $I C O S$ were contained within a $100-\mathrm{kb}$ block of strong intermarker LD, flanked by two regions of low LD (between CD28 and CTLA4) and this block was considered to contain the causal variant. Within this block were three main peaks of association, the first peak was $20-35 \mathrm{~kb} 5^{\prime}$ of the CTLA4 ATG codon, the second was $0 \cdot 2-6 \cdot 3 \mathrm{~kb} 3^{\prime}$ of the previously reported end of the CTLA4 transcript and the third was $49-50 \mathrm{~kb}$ $3^{\prime}$ of the CTLA4 transcript end and 8-13 kb 5' of the ICOS ATG codon [51]. Regression analysis eliminated the third peak as containing the aetiological variant and the first peak was subsequently eliminated when an extended data set was scored leaving the second peak as the most associated. The second peak contained SNPs CT60, JO31, JO30 and JO27-1, with CT60 being the most associated with GD and Hashimoto's thyroiditis (HT) producing RRs of 1.51 and 1.45 , respectively [51]. Further support was gained from family studies but regression analysis failed to distinguish which SNP out of CT60, JO31, JO30 or JO27-1 was 
Table 3. Case control association studies of the four originally investigated CTLA-4 SNPs within GD and HT datasets of differing ethnic origin

\begin{tabular}{|c|c|c|c|c|c|}
\hline Author/year & Reference & Size of data set (n) & Population & AITD disease & Relative risk (RR) \\
\hline \multicolumn{6}{|l|}{$C T L A-4(\mathrm{AT}) \mathrm{n}$} \\
\hline Yanagawa et al. 1995 & [46] & 218 & Caucasians (USA) & GD & $2 \cdot 8$ \\
\hline \multirow[t]{2}{*}{ Kotsa et al. 1997} & [93] & 203 & Caucasian (UK) & GD & $2 \cdot 1$ \\
\hline & & 135 & Caucasian (UK) & HT & $2 \cdot 2$ \\
\hline Petrone et al. 2001 & {$[92]$} & 427 & Caucasian (Italian) & HT & $\mathrm{N} / \mathrm{S}$ \\
\hline \multicolumn{6}{|l|}{$C T L A-4(49) \mathrm{A} / \mathrm{G}$} \\
\hline Nistico et al. 1996 & {$[47]$} & 171 & Hong Kong Chinese & GD & $1 \cdot 7$ \\
\hline Donner et al. 1997 & {$[94]$} & 630 & Caucasian (German \& Canadian) & GD & $1 \cdot 6$ \\
\hline Donner et al. 1997 & [95] & 539 & Caucasian (German \& Canadian) & HT & $1 \cdot 6$ \\
\hline Djilali-Saiah et al. 1998 & [96] & 173 & Caucasian (French) & GD & $\mathrm{N} / \mathrm{S}$ \\
\hline Heward et al. 1999 & {$[48]$} & 743 & Caucasian (UK) & GD & $1 \cdot 58$ \\
\hline Vaidya et al. 1999 & {$[22]$} & 286 & Caucasian (UK) & GD & $1 \cdot 8$ \\
\hline Buzzetti et al. 1999 & [97] & 336 & Caucasian (Italian) & GD & $1 \cdot 8$ \\
\hline Villanueva et al. 2000 & {$[98]$} & 258 & Caucasians (USA) & GD & $1 \cdot 6$ \\
\hline Allahabadia et al. 2001 & [99] & 908 & Caucasian (UK) & GD & $1 \cdot 8$ \\
\hline Petrone et al. 2001 & {$[92]$} & 427 & Caucasian (Italian) & HT & $\mathrm{N} / \mathrm{S}$ \\
\hline Nithiyananthan et al. 2002 & {$[100]$} & 532 & Caucasian (UK) & HT & $1 \cdot 57$ \\
\hline Vaidya et al. 2003 & & 650 & Caucasian (UK) & GD & $1 \cdot 65$ \\
\hline \multicolumn{6}{|l|}{$C T L A-4(-318) \mathrm{C} / \mathrm{T}$} \\
\hline \multirow[t]{2}{*}{ Heward et al. 1998} & {$[101]$} & 546 & Caucasian (UK) & GD & $\mathrm{N} / \mathrm{S}$ \\
\hline & & 180 & Hong Kong Chinese & GD & $\mathrm{N} / \mathrm{S}$ \\
\hline \multirow[t]{3}{*}{ Braun et al. 1998} & {$[102]$} & 447 & Caucasian (UK) & HT & $\mathrm{N} / \mathrm{S}$ \\
\hline & & 298 & Caucasian (German \& Canadian) & GD & $2 \cdot 22$ \\
\hline & & 237 & Caucasian (German \& Canadian) & HT & $\mathrm{N} / \mathrm{S}$ \\
\hline \multicolumn{6}{|l|}{$C T L A-4(1822) \mathrm{C} / \mathrm{T}$} \\
\hline Vaidya et al. 2003 & {$[103]$} & 650 & Caucasian (UK) & GD & $1 \cdot 64$ \\
\hline
\end{tabular}

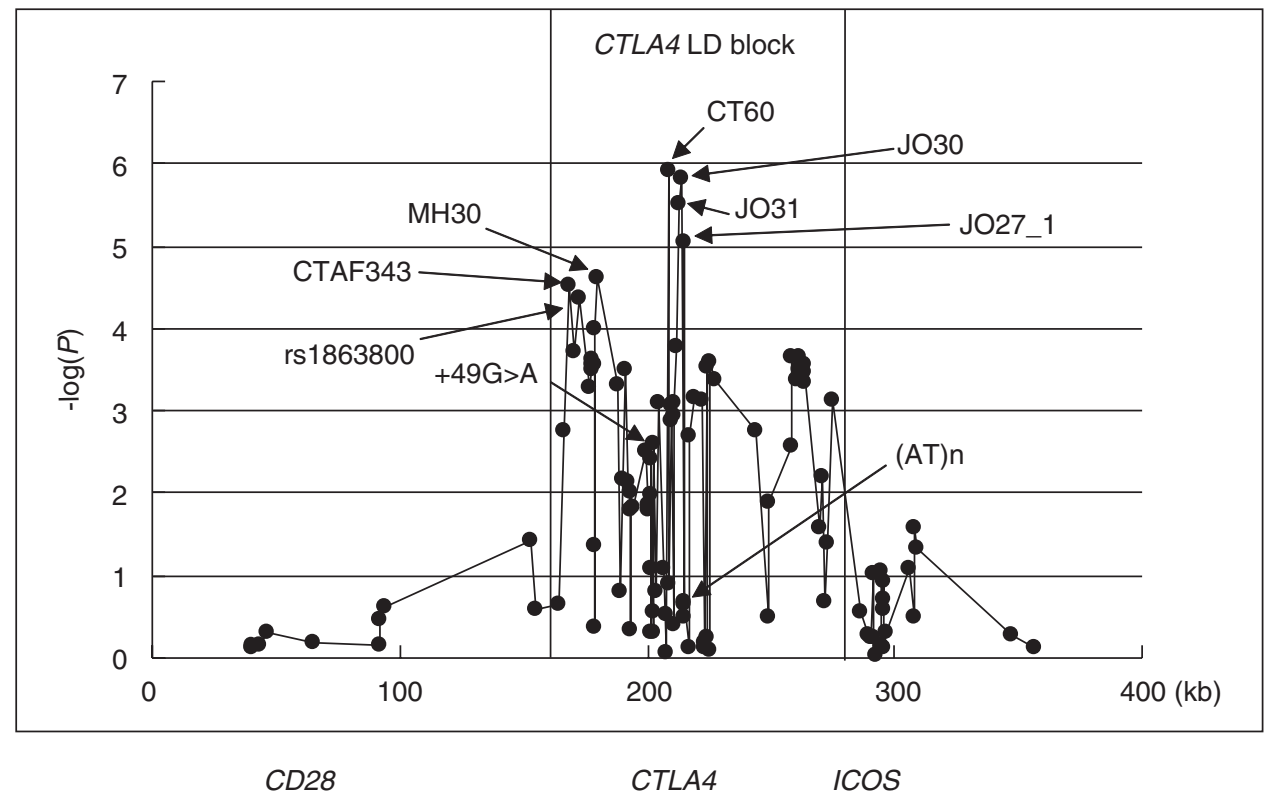

Fig. 4. Association of SNPs within the CD28-CTLA4-ICOS gene region with GD. When association with GD was plotted for all the SNPs, a region consisting of CTLA-4 and 5' ICOS gene (CTLA4 LD BLOCK) was believed to contain the aetiological variant. This diagram highlights the CT60-JO30-JO31-J027-1 peak of linkage that is believed to contain the aetiological variant associated with GD and HT (reprinted by permission from Nature 2003; 423:506-511. Copyright 2003, Macmillan Publishers Ltd.) 
the aetiological variant. Although susceptibility to GD and AIH has been mapped to a noncoding $6 \cdot 1 \mathrm{~kb} 3^{\prime}$ region of $C T L A-4$, it is important to note that other causal variants outside this region, including smaller effects and those $5^{\prime}$ of CTLA-4 have not been completely excluded.

Further functional analysis examined steady state mRNA levels of two isoforms of CTLA-4: a full length isoform (flCTLA-4) encoded by exons 1-4 and a soluble form (sCTLA-4) that lacks exon 3 (transmembrane domain) [51]. The ratio of sCTLA-4 to flCTLA-4 mRNA splice forms in unstimulated CD4 T cells was $50 \%$ lower in CT60 G/G positive disease-susceptible individuals compared with the A/A protected individuals $(P=0.002)$, suggesting that the $6 \cdot 1 \mathrm{~kb}$ region determines the efficiency of splicing and production of sCTLA-4, with the CT60G disease-susceptibility haplotype producing less sCTLA-4 transcript than the CT60A haplotype [51]. Whilst additional minor genetic effects can not be completely excluded it seems likely from this study that susceptibility to AITD conferred by the CD28/CTLA-4/ ICOS locus is the result of polymorphism within CTLA-4 itself. The most associated GD SNPs were also found to be associated with T1D and AIH supporting the hypothesis that CTLA-4 is acting as a susceptibility locus for autoimmune disease in general.

There are several potential mechanisms whereby polymorphism of CTLA-4 may have an effect on the counter regulation of the CD28 costimulatory signal and confer susceptibility to AITD and autoimmune disease in general. The competition between CTLA-4, and CD28 for each of the CD80 and CD86 receptors may be influenced by $C T L A-4$ genotype. Furthermore, soluble CTLA-4 is present in human serum [52-54], can bind to CD80/ CD86 and may inhibit $\mathrm{T}$ cell proliferation via increased activation of CD28 [54]. CTLA-4 is also constitutively expressed by T regulatory cells ( $\mathrm{T}$ reg) [55-57], deletion of which has been shown in animal models to lead to autoimmune disease [58-60]. Some of the $\mathrm{T}$ reg function is mediated by CTLA- 4 binding to the CD80/ CD86 receptors $[57,61,62]$ such that $T$ effector activity could be determined by CTLA-4 genotype. Whilst these hypotheses are by no means exhaustive nor mutually exclusive, the fine mapping of $C T L A-4$ susceptibility locus has opened up a large area for future studies which will increase our understanding of the autoimmune disease process.

\section{BEYOND HLA AND CTLA-4}

The $H L A$ and $C T L A-4$ regions may contribute to around $50 \%$ of the susceptibility to AITD. The identification of further susceptibility loci, as for most complex diseases, has involved a large number of both candidate gene and genome wide linkage studies. Whilst attractive candidate genes have been the focus of intense investigation and a number of chromosomal regions have been linked to disease, the identification of a third locus for AITD is eagerly awaited.

Candidate gene studies have focused on disease specific loci and numerous immune response genes including TSHR, Interleukin-1, Interleukin-1 Receptor Antagonist, Large Multifunctional Protein 2 and 7 and autoimmune regulator 1 gene [63-70]. Many of these studies have produced confusing and conflicting results with no clear evidence of consistent replication. The explanation for such a diversity of results is almost certainly small sample size and also the first time effect phenomenon [71], where the first time an effect is detected it is much greater than in subsequent studies. This leaves the role of other genes in AITD in controversy, with only $H L A$ and $C T L A-4$ showing consistent association.

Genome wide screens have, to date, proved no more successful than candidate gene studies in terms of delivering a novel locus. The first genome wide screen in GD in 56 multiplex families reported three areas of linkage designated GD-1 on chromosome 14q31, GD-2 on chromosome 20q11.2 and GD-3 on chromosome Xq21. Subsequently two further regions of linkage have been reported to AIH, HT1 on chromosome 13q33, HT2 on chromosome $12 \mathrm{q} 22$, and one area of linkage to AITD in general, AITD1 on $6 p$ close to, but distinct to HLA [72]. Upon increasing the number of families to 102 and repeating the genome screen, some support was gained for GD-1, GD-2 and HT-2, with GD-3 and HT-1 no longer appearing associated and the exact position of AITD-1 on $6 p$ being questioned [73]. Independent attempts to replicate these findings have been largely unsuccessful [74,75]. Sakai et al. [76] have reported linkage to AITD on chromosome 5q31-33 in a Japanese sib-pair family dataset. This region is of particular interest as it contains a large cytokine gene cluster including $I L-3, I L-9, I L-13$ and in particular $I L-4$ and $I L-5$ that may play a role in $\mathrm{Th} 2$ responses that lead to $\mathrm{AIH}$, with replication being eagerly awaited.

Genome-wide linkage analysis of Japanese sib-pairs recently demonstrated suggestive evidence for linkage between chromosome 8q23-q24 and HT [76]. Linkage analysis of a further data set of families with AITD replicated this original finding with evidence of allelic association between subjects with AITD and two chromosomal markers on chromosome 8q23-q24 namely Tgms2, located within the thyroglobulin ( Tg) gene and D8S284, in the $T g$ region [77]. As human $\mathrm{Tg}$ is a major autoantigen for thyroid disease and is present in almost all patients with AITD [78-80], $\mathrm{Tg}$ on chromosome 8q23-24 is a good candidate gene for AITD. We have performed a case control association study on patients with AITD and controls in the UK [81]. No differences in allele frequencies were observed between AITD cases and controls for D8S284. Compared with the 3 common alleles (frequencies $>10 \%$ ) the rare alleles of Tgms 2 were, however, increased, $P=0.001$ at Tgms2. This group included the $336 \mathrm{bp}$ allele (increased in cases versus controls, $P<0.001$ ) which has previously been reported to be associated with AITD. Whilst these findings may represent a random chance event, taken together with previous reports of linkage and association, this may be an example of a rare causal variant of a complex disease. Subsequent to this, resequencing of $T g$ has identified 14 novel SNPs, 3 of which in exons 10, 12 and 33 have been reported to be associated with AITD [82]. Resequencing of the same exons of the mouse $T g$ revealed a unique SNP haplotype present in $50 \%$ of mouse strains susceptible to thyroiditis which was not present in strains resistant to thyroiditis. This exciting work clearly needs replication in an independent data set. Furthermore, the authors also concluded that polymorphism within $\mathrm{Tg}$ may not be the primary aetiological variant and polymorphism in a neighbouring gene can not be excluded as conferring susceptibility to AITD.

Whilst both the HLA and CTLA-4 regions have been reported to be linked to GD in a UK data set, neither region has been detected in the genome screens described above. The reasons for this seem to relate to the individual contribution of each locus to disease. Unlike T1D [20] for example, the $H L A$ region is not exerting a major effect in AITD as reflected in the odds ratios 
observed in association studies [2]. Whilst CTLA-4 region is exerting a greater effect in AITD compared with T1D, its contribution is still modest, and probably of the same order of magnitude to that seen regarding the insulin gene region in T1D which has not been detected by linkage analysis in many large T1D family data sets [83]. The general lack of linkage to HLA and CTLA-4 regions in genome wide linkage analyses is however, an important observation. This clearly suggests that novel candidates have failed to be identified because there is no single gene region exerting a major effect in AITD and that other as yet unknown loci are likely to be of a similar or smaller magnitude than $H L A$ and CTLA-4.

\section{CONCLUSIONS AND FUTURE DIRECTIONS}

Over the last 10 years we have only seen the identification of one new susceptibility gene (CTLA-4) for AITD and a third locus $(T g)$, awaits confirmation. However, with the publication of the draft human genome [84], the establishment of SNP maps, the resequencing of many immune response genes and the development of faster, more effective, high throughput genotyping methods, there is now some sense of optimism that new loci will be identified. The funding of large national DNA collections will also help overcome the problems of inadequately sized data sets and increase our chances of detecting individual genetic effects contributing to AITD most of which are likely to be smaller than originally envisaged.

\section{REFERENCES}

1 Tunbridge WM, Evered DC, Hall R et al. The spectrum of thyroid disease in a community: the Whickham survey. Clin Endocrinol 1977; 7:481-93.

2 Gough SC. The genetics of Graves' disease. Endocrinol Metab Clin North Am 2000; 29:255-66.

3 Tait K, Marshall T, Berman J et al. Clustering of autoimmune disease in parents of siblings from type 1 diabetes Warren Repository. Diabetic Medicine 2004; 00:000-000. in press.

4 Mosmann TR, Sad S. The expanding universe of T-cell subsets: Th1, Th2 and more. Immunol Today 1996; 17:138-46.

5 Bluher M, Krohn K, Wallaschofski H, Braverman LE, Paschke R. Cytokine gene expression in autoimmune thyroiditis in BioBreeding/ Worcester rats. Thyroid 1999; 9:1049-55.

6 Ruwhof C, Drexhage HA. Iodine and thyroid autoimmune disease in animal models. Thyroid 2001; 11:427-36.

7 Voorby HA, Kabel PJ. de Haan M, Jeucken PH, van der Gaag RD, de Baets MH, Drexhage HA. Dendritic cells and class II MHC expression on thyrocytes during the autoimmune thyroid disease of the BB rat. Clin Immunol Immunopathol 1990; 55:9-22.

8 Roura-Mir C, Catalfamo M, Sospedra M, Alcalde L, Pujol-Borrell R, Jaraquemada D. Single-cell analysis of intrathyroidal lymphocytes shows differential cytokine expression in Hashimoto's and Graves' disease. Eur J Immunol 1997; 27:3290-302.

9 Bretz JD, Arscott PL, Myc A, Baker JR Jr. Inflammatory cytokine regulation of Fas-mediated apoptosis in thyroid follicular cells. J Biol Chem 1999; 274:25433-8.

10 Stassi G, Di Liberto D, Todaro M et al. Control of target cell survival in thyroid autoimmunity by $\mathrm{T}$ helper cytokines via regulation of apoptotic proteins. Nat Immunol 2000; 1:483-8.

11 Bartels ED. Twin examinations/Heredity in Graves' disease. Einar Copenhagen: Munksgaard, 1941:33-6 (Thesis).

12 Harvald B, Hauge M. Catamnestic investigation of Danish twins; a preliminary report. Dan Med Bull 1956; 3:150-8.
13 Brix TH, Kyvik KO, Christensen K, Hegedus L. Evidence for a major role of heredity in Graves' disease. a population-based study of two Danish twin cohorts. J Clin Endocrinol Metab 2001; 86:930-4.

14 Brix TH, Kyvik KO, Hegedus L. A population-based study of chronic autoimmune hypothyroidism in Danish twins. J Clin Endocrinol Metab 2000; 85:536-9.

15 Valtonen VV, Ruutu P, Varis K, Ranki M, Malkamaki M, Makela P. Serological evidence for the role of bacterial infections in the pathogenesis of thyroid diseases. Acta Med Scand 1986; 219:105-11.

16 Jaspan JB, Sullivan K, Garry RF et al. The interaction of a type A retroviral particle and class II human leukocyte antigen susceptibility genes in the pathogenesis of Graves' disease. J Clin Endocrinol Metab 1996; 81:2271-9.

17 Kung AW. Life events, daily stresses and coping in patients with Graves' disease. Clin Endocrinol 1995; 42:303-8.

18 Brucker-Davis F. Effects of environmental synthetic chemicals on thyroid function. Thyroid 1998; 8:827-56.

19 McIver B, Morris JC. The pathogenesis of Graves' disease. Endocrinol Metab Clin North Am 1998; 27:73-89.

20 Todd JA. Genetic analysis of type 1 diabetes using whole genome approaches. Proc Natl Acad Sci USA 1995; 92:8560-5.

21 Allahabadia A, Gough SC. The different approaches to the genetic analysis of autoimmune thyroid disease. J Endocrinol 1999; 163:7-13.

22 Vaidya B, Imrie H, Perros P et al. The cytotoxic T lymphocyte antigen4 is a major Graves' disease locus. Hum Mol Genet 1999; 8:1195-9.

23 Nithiyananthan R, Gough SC. Genetics of Graves' disease. In: Dutton J, Haik B, eds. Thyroid eye disease. New York: Marcel Dekker, 2002:113-25.

24 Grumet FC, Payne RO, Konishi J, Kriss JP. HL-A antigens as markers for disease susceptibility and autoimmunity in Graves' disease. J Clin Endocrinol Metab 1974; 39:1115-9.

25 Farid NR, Barnard JM, Marshall WH. The association of HLA with autoimmune thyroid disease in Newfoundland. The influence of HLA homozygosity in Graves' disease. Tissue Antigens 1976; 8:181-9.

26 Mather BA, Roberts DF, Scanlon MF, Mukhtar ED, Davies TF, Smith BR, Hall R. HLA antigens and thyroid autoantibodies in patients with Graves' disease and their first degree relatives. Clin Endocrinol 1980; 12:155-63.

27 Bech K, Lumholtz B, Nerup J etal. HLA antigens in Graves' disease. Acta Endocrinol 1977; 86:510-6.

28 Farid NR, Sampson L, Noel EP, Barnard JM, Mandeville R, Larsen B, Marshall WH, Carter ND. A study of human leukocyte D locus related antigens in Graves' disease. J Clin Invest 1979; 63:108-13.

29 Allanic H, Fauchet R, Lorcy Y, Heim J, Gueguen M, Leguerrier AM, Genetet B. Graves' disease. Predominance of the DRw3 antigen (author's transl). Nouv Presse Med 1980; 9:1823-6.

30 Dahlberg PA, Holmlund G, Karlsson FA, Safwenberg J. HLA-A-B$\mathrm{C}$ and - DR antigens in patients with Graves' disease and their correlation with signs and clinical course. Acta Endocrinol 1981; 97:427.

31 Boehm BO, Kuhnl P, Manfras BJ etal. HLA-DRB3 gene alleles in Caucasian patients with Graves' disease. Clin Invest 1992; 70:956-60.

32 Ito M, Tanimoto M, Kamura H etal. Association of HLA antigen and restriction fragment length polymorphism of $\mathrm{T}$ cell receptor betachain gene with Graves' disease and Hashimoto's thyroiditis. J Clin Endocrinol Metab 1989; 69:100-4.

33 Yanagawa T, Mangklabruks A, Chang YB, Okamoto Y, Fisfalen ME, Curran PG, DeGroot LJ. Human histocompatibility leukocyte antigen-DQA1*0501 allele associated with genetic susceptibility to Graves' disease in a Caucasian population. J Clin Endocrinol Metab 1993; 76:1569-74.

34 Barlow AB, Wheatcroft N, Watson P, Weetman AP. Association of HLA-DQA1*0501 with Graves' disease in English Caucasian men and women. Clin Endocrinol 1996; 44:73-7.

35 Cuddihy RM, Bahn RS. Lack of an independent association between the human leukocyte antigen allele DQA1*0501 and Graves' disease. J Clin Endocrinol Metab 1996; 81:847-9. 
36 Hunt PJ, Marshall SE, Weetman AP, Bunce M, Bell JI, Wass JA, Welsh KI. Histocompatibility leucocyte antigens and closely linked immunomodulatory genes in autoimmune thyroid disease. Clin Endocrinol 2001; 55:491-9.

37 Maciel LM, Rodrigues SS, Dibbern RS, Navarro PA, Donadi EA. Association of the HLA-DRB1*0301 and HLA-DQA $1 * 0501$ alleles with Graves' disease in a population representing the gene contribution from several ethnic backgrounds. Thyroid 2001; 11:31-5.

38 Yanagawa T, Mangklabruks A, DeGroot LJ. Strong association between HLA-DQA1*0501 and Graves' disease in a male Caucasian population. J Clin Endocrinol Metab 1994; 79:227-9.

39 Heward JM, Allahabadia A, Daykin J etal. Linkage disequilibrium between the human leukocyte antigen class II region of the major histocompatibility complex and Graves' disease: replication using a population case control and family-based study. J Clin Endocrinol Metab 1998; 83:3394-7.

40 Moens H, Farid NR, Sampson L, Noel EP, Barnard JM. Hashimoto's thyroiditis is associated with HLA-DRw3. N Engl J Med 1978; 299:133-4.

41 Tandon N, Zhang L, Weetman AP. HLA associations with Hashimoto's thyroiditis. Clin Endocrinol 1991; 34:383-6.

42 Mueller DL, Jenkins MK, Schwartz RH. Clonal expansion versus functional clonal inactivation: a costimulatory signalling pathway determines the outcome of $\mathrm{T}$ cell antigen receptor occupancy. Annu Rev Immunol 1989; 7:445-80.

43 Walunas TL, Lenschow DJ, Bakker CY, Linsley PS, Freeman GJ, Green JM, Thompson CB, Bluestone JA. CTLA-4 can function as a negative regulator of T cell activation. Immunity 1994; 1:405-13.

44 Egen JG, Kuhns MS, Allison JP. CTLA-4: new insights into its biological function and use in tumor immunotherapy. Nat Immunol 2002; 3:611-8.

45 Marron MP, Zeidler A, Raffel LJ etal. Genetic and physical mapping of a type 1 diabetes susceptibility gene (IDDM12) to a 100-kb phagemid artificial chromosome clone containing D2S72-CTLA4D2S105 on chromosome 2q33. Diabetes 2000; 49:492-9.

46 Yanagawa T, Hidaka Y, Guimaraes V, Soliman M, DeGroot LJ. CTLA-4 gene polymorphism associated with Graves' disease in a Caucasian population. J Clin Endocrinol Metab 1995; 80:41-5.

47 Nistico L, Buzzetti R, Pritchard LE etal. The CTLA-4 gene region of chromosome 2q33 is linked to, and associated with, type 1 diabetes. Belgian Diabetes Registry. Hum Mol Genet 1996; 5:1075-80.

48 Heward JM, Allahabadia A, Armitage M et al. The development of Graves' disease and the CTLA-4 gene on chromosome 2q33. J Clin Endocrinol Metab 1999; 84:2398-401.

49 Kouki T, Sawai Y, Gardine CA, Fisfalen ME, Alegre ML, DeGroot LJ. CTLA-4 gene polymorphism at position 49 in exon 1 reduces the inhibitory function of CTLA- 4 and contributes to the pathogenesis of Graves' disease. J Immunol 2000; 165:6606-11.

50 Krummel MF, Allison JP. CTLA-4 engagement inhibits IL-2 accumulation and cell cycle progression upon activation of resting T cells. J Exp Med 1996; 183:2533-40.

51 Ueda H, Howson JM, Esposito L et al. Association of the T-cell regulatory gene CTLA4 with susceptibility to autoimmune disease. Nature 2003; 423:506-11.

52 Magistrelli G, Jeannin P, Herbault N, Benoit De Coignac A, Gauchat JF, Bonnefoy JY, Delneste Y. A soluble form of CTLA-4 generated by alternative splicing is expressed by nonstimulated human $\mathrm{T}$ cells. Eur J Immunol 1999; 29:3596-602.

53 Oaks MK, Hallett KM. Cutting edge: a soluble form of CTLA-4 in patients with autoimmune thyroid disease. J Immunol 2000; 164:50158.

54 Oaks MK, Hallett KM, Penwell RT, Stauber EC, Warren SJ, Tector AJ. A native soluble form of CTLA-4. Cell Immunol 2000; 201:14453.

55 Finger EB, Bluestone JA. When ligand becomes receptor - tolerance via B7 signaling on DCs. Nat Immunol 2002; 3:1056-7.

56 Asano M, Toda M, Sakaguchi N, Sakaguchi S. Autoimmune disease as a consequence of developmental abnormality of a $\mathrm{T}$ cell subpopulation. J Exp Med 1996; 184:387-96.

57 Manzotti CN, Tipping H, Perry LC, Mead KI, Blair PJ, Zheng Y, Sansom DM. Inhibition of human T cell proliferation by CTLA-4 utilizes CD80 and requires CD25+ regulatory T cells. Eur J Immunol 2002; 32:2888-96.

58 Maloy KJ, Salaun L, Cahill R, Dougan G, Saunders NJ, Powrie F. CD4+CD25+ T (R) cells suppress innate immune pathology through cytokine-dependent mechanisms. J Exp Med 2003; 197:111-9.

59 Sakaguchi S. Control of immune responses by naturally arising CD4+ regulatory T cells that express toll-like receptors. J Exp Med 2003; 197:397-401.

60 Pasare C, Medzhitov R. Toll pathway-dependent blockade of CD4+CD25+ T cell-mediated suppression by dendritic cells. Science 2003; 299:1033-6.

61 Grohmann U, Orabona C, Fallarino F etal. CTLA-4-Ig regulates tryptophan catabolism in vivo. Nat Immunol 2002; 3:1097-101.

62 Lin H, Rathmell JC, Gray GS, Thompson CB, Leiden JM, Alegre ML. Cytotoxic T lymphocyte antigen 4 (CTLA4) blockade accelerates the acute rejection of cardiac allografts in CD28-deficient mice. CTLA4 can function independently of CD28. J Exp Med 1998; 188:199-204.

63 Cuddihy RM, Dutton CM, Bahn RS. A polymorphism in the extracellular domain of the thyrotropin receptor is highly associated with autoimmune thyroid disease in females. Thyroid 1995; 5:89-95.

64 Allahabadia A, Heward JM, Mijovic C etal. Lack of association between polymorphism of the thyrotropin receptor gene and Graves' disease in United Kingdom and Hong Kong Chinese patients: case control and family-based studies. Thyroid 1998; 8:777-80.

65 Hunt PJ, Marshall SE, Weetman AP, Bell JI, Wass JA, Welsh K. I. Association of Graves' disease with an allele of the interleukin-1 receptor antagonist gene. J Clin Endocrinol Metab 2000; 80:111-5.

66 Heward JM, Nithiyananthan R, Allahabadia A, Gibson S, Franklyn JA, Gough SC. No association of an interleukin 4 gene promoter polymorphism with Graves' disease in the United Kingdom. J Clin Endocrinol Metab 2001; 86:3861-3.

67 Blakemore AI, Watson PF, Weetman AP, Duff GW. Association of Graves' disease with an allele of the interleukin-1 receptor antagonist gene. J Clin Endocrinol Metab 1995; 80:111-5.

68 Heward J, Allahabadia A, Gordon C, Sheppard MC, Barnett AH, Franklyn JA, Gough SC. The interleukin-1 receptor antagonist gene shows no allelic association with three autoimmune diseases. Thyroid 1999; 9:627-8.

69 Heward JM, Allahabadia A, Sheppard MC, Barnett AH, Franklyn JA, Gough SC. Association of the large multifunctional proteasome (LMP2) gene with Graves' disease is a result of linkage disequilibrium with the HLA haplotype DRB1*0304-DQB1*02-DQA1*0501. Clin Endocrinol 1999; 51:115-8.

70 Nithiyananthan R, Heward JM, Allahabadia A, Barnett AH, Franklyn JA, Gough SC. A heterozygous deletion of the autoimmune regulator (AIRE1) gene, autoimmune thyroid disease, and type 1 diabetes: no evidence for association. J Clin Endocrinol Metab 2000; 85:1320-2.

71 Ioannidis JP, Ntzani EE, Trikalinos TA, Contopoulos-Ioannidis DG. Replication validity of genetic association studies. Nat Genet 2001; 29:306-9.

72 Tomer Y, Barbesino G, Greenberg DA, Concepcion E, Davies TF. Mapping the major susceptibility loci for familial Graves' and Hashimoto's diseases: evidence for genetic heterogeneity and gene interactions. J Clin Endocrinol Metab 1999; 84:4656-64.

73 Tomer Y, Ban Y, Concepcion E, Barbesino G, Villanueva R, Greenberg DA, Davies TF. Common and unique susceptibility Loci in graves and hashimoto diseases: results of whole-genome screening in a data set of 102 multiplex families. Am J Hum Genet 2003; 73:73647.

74 Imrie H, Vaidya B, Perros P, Kelly WF, Toft AD, Young ET, KendallTaylor P, Pearce SH. Evidence for a Graves' disease susceptibility 
locus at chromosome Xp11 in a United Kingdom population. J Clin Endocrinol Metab 2001; 86:626-30.

75 Ban Y, Davies TF, Greenberg DA, Concepcion ES, Tomer Y. The influence of human leucocyte antigen (HLA) genes on autoimmune thyroid disease (AITD): results of studies in HLA-DR3 positive AITD families. Clin Endocrinol 2002; 57:81-8.

76 Sakai K, Shirasawa S, Ishikawa N etal. dentification of susceptibility loci for autoimmune thyroid disease to 5q31-q33 and Hashimoto's thyroiditis to 8q23-q24 by multipoint affected sib-pair linkage analysis in Japanese. Hum Mol Genet 2001; 10:1379-86.

77 Tomer Y, Greenberg DA, Concepcion E, Ban Y, Davies TF. Thyroglobulin is a thyroid specific gene for the familial autoimmune thyroid diseases. J Clin Endocrinol Metab 2002; 87:404-7.

78 Tomer Y. Anti-thyroglobulin autoantibodies in autoimmune thyroid diseases: cross-reactive or pathogenic? Clin Immunol Immunopathol 1997; 82:3-11.

79 Baas F, van Ommen GJ, Bikker H, Arnberg AC, de Vijlder JJ. The human thyroglobulin gene is over $300 \mathrm{~kb}$ long and contains introns of up to $64 \mathrm{~kb}$. Nucl Acids Res 1986; 14:5171-86.

80 van de Graaf SA, Ris-Stalpers C, Pauws E, Mendive FM, Targovnik HM, de Vijlder JJ. Up to date with human thyroglobulin. J Endocrinol 2001; 170:307-21.

81 Collins JE, Heward JM, Carr-Smith J, Daykin J, Franklyn JA, Gough SC. Association of a rare thyroglobulin gene microsatellite variant with autoimmune thyroid disease. J Clin Endocrinol Metab 2003; 88:5039-42.

82 Ban Y, Greenberg DA, Concepcion E, Skrabanek L, Villanueva R, Tomer Y. Amino acid substitutions in the thyroglobulin gene are associated with susceptibility to human and murine autoimmune thyroid disease. Proceedings of the Natl Acad Sci USA 2003.

83 Concannon P, Gogolin-Ewens KJ, Hinds DA et al. A secondgeneration screen of the human genome for susceptibility to insulindependent diabetes mellitus. Nat Genet 1998; 19:292-6.

$84 \mathrm{McPherson}$ JD, Marra M, Hillier L et al. A physical map of the human genome. Nature 2001; 409:934-41.

85 Mangklabruks A, Cox N, DeGroot LJ. Genetic factors in autoimmune thyroid disease analyzed by restriction fragment length polymorphisms of candidate genes. J Clin Endocrinol Metab 1991; 73:23644.

86 Badenhoop K, Schwarz G, Schleusener H, Weetman AP, Recks S, Peters H, Bottazzo GF, Usadel KH. Tumor necrosis factor beta gene polymorphisms in Graves' disease. J Clin Endocrinol Metab 1992; 74:287-91.

87 Badenhoop K, Walfish PG, Rau H, Fischer S, Nicolay A, Bogner U, Schleusener H, Usadel KH. Susceptibility and resistance alleles of human leukocyte antigen (HLA) DQA1 and HLA DQB1 are shared in endocrine autoimmune disease. J Clin Endocrinol Metab 1995; 80:2112-7.

88 Philippou G, Krimitzas A, Kaltsas G, Anastasiou E, Souvatzoglou A, Alevizaki M. HLA DQA1*0501 and DRB1*0301 antigens do not independently convey susceptibility to Graves' disease. J Endocrinol Invest 2001; 24:88-91.

89 Weissel M, Hofer R, Zasmeta H, Mayr WR. HLA-DR and Hashimoto's thyroiditis. Tissue Antigens 1980; 16:256-7.

90 Jenkins D, Penny MA, Fletcher JA, Jacobs KH, Mijovic CH, Franklyn JA, Sheppard MC. HLA class II gene polymorphism contributes little to Hashimoto's thyroiditis. Clin Endocrinol 1992; 37:141-5.

91 Wan XL, Kimura A, Dong RP, Honda K, Tamai H, Sasazuki T. HLAA and -DRB4 genes in controlling the susceptibility to Hashimoto's thyroiditis. Hum Immunol 1995; 42:131-6.

92 Petrone A, Giorgi G, Mesturino CA etal. Association of DRB1*04DQB1*0301 haplotype and lack of association of two polymorphic sites at CTLA-4 gene with Hashimoto's thyroiditis in an Italian population. Thyroid 2001; 11:171-5.

93 Kotsa K, Watson PF, Weetman AP. A CTLA-4 gene polymorphism is associated with both Graves disease and autoimmune hypothyroidism. Clin Endocrinol 1997; 46:551-4.

94 Donner H, Rau H, Walfish PG et al. CTLA4 alanine-17 confers genetic susceptibility to Graves' disease and to type 1 diabetes mellitus. J Clin Endocrinol Metab 1997; 82:143-6.

95 Donner H, Braun J, Seidl C etal. Codon 17 polymorphism of the cytotoxic T lymphocyte antigen 4 gene in Hashimoto's thyroiditis and Addison's disease. J Clin Endocrinol Metab 1997; 82:4130-2.

96 Djilali-Saiah I, Larger E, Harfouch-Hammoud E etal. No major role for the CTLA-4 gene in the association of autoimmune thyroid disease with IDDM. Diabetes 1998 ; 47:125-7.

97 Buzzetti R, Nistico L, Signore A, Cascino I. CTLA-4 HLA gene susceptibility to thyroid-associated orbitopathy. Lancet 1999;354:1824.

98 Villanueva R, Inzerillo AM, Tomer Y et al. Limited genetic susceptibility to severe Graves' ophthalmopathy: no role for CTLA-4 but evidence for an environmental etiology. Thyroid 2000; 10:791-8.

99 Allahabadia A, Heward JM, Nithiyananthan R, Gibson SM, Reuser TT, Dodson PM, Franklyn JA, Gough SC. MHC class II region, CTLA4 gene, and ophthalmopathy in patients with Graves' disease. Lancet 2001; 358:984-5.

100 Nithiyananthan R, Heward JM, Allahabadia A, Franklyn JA, Gough SC. Polymorphism of the CTLA-4 gene is associated with autoimmune hypothyroidism in the United Kingdom. Thyroid 2002; 12:3-6.

101 Heward JM, Allahabadia A, Carr-Smith J et al. No evidence for allelic association of a human CTLA-4 promoter polymorphism with autoimmune thyroid disease in either population-based case-control or family-based studies. Clin Endocrinol 1998; 49:331-4.

102 Braun J, Donner H, Siegmund T, Walfish PG, Usadel KH\& Badenhoop, K. CTLA-4 promoter variants in patients with Graves' disease and Hashimoto's thyroiditis. Tissue Antigens 2003; 51:563-6.

103 Vaidya B, Oakes EJ, Imrie H, Dickinson AJ, Perros P, KendallTaylor P, Pearce SH. CTLA4 gene and Graves' disease: association of Graves' disease with the CTLA4 exon 1 and intron 1 polymorphisms, but not with the promoter polymorphism. Clin Endocrinol 1998; 58:732-5. 